\title{
Effect of type of aversive event and warning signal duration on human avoidance performance*
}

\author{
DANIEL L. KOCH and GENE H. MOFFAT \\ University of Southern Mississippi, Hattiesburg, Mississippi 39401
}

\begin{abstract}
Sixty college Ss were given 40 leverpress avoidance trials, with omission of entertaining material or a 98-dB or a 120-dB tone serving as the aversive stimulus. Within each aversive stimulus group, one-half of the Ss received a 2 -sec warning signal; for the remaining Ss the signal duration was 6 sec. Response latency was the only measure that reflected differences in avoidance performance for the variables investigated. A functional equivalence for the two types of aversive stimulus events was supported.
\end{abstract}

A wide variety of stimuli have been employed as aversive events in instrumental avoidance conditioning situations in human Ss. In free-operant studies, the periodic withdrawal of positive reinforcing stimuli such as coins (e.g., Baron \& Kaufman, 1966), point loss (e.g., Weiner, 1963), and cartoons (e.g., Baer, 1960), as well as the presentation of noxious stimuli such as electric shock (e.g., Ader \& Tatum, 1961) and white noise (e.g., Presbie, 1970) have been used. In discrete-trial avoidance experiments, electric shock (e.g., Banks, 1965), loud tones (e.g., Penny \& Croskery, 1962), and air blasts (e.g., Miller, Kalin, Eckenroth, \& Meyer, 1970) have been the most commonly used noxious stimuli. In addition, withdrawal of positive reinforcing stimuli such as children's stories (Moffat, 1972) and entertaining material (e.g., Moffat \& Miller, 1970) have been employed effectively as aversive stimuli in discrete-trial avoidance conditioning experiments.

While these experiments have reported success with these various aversive stimulus events, little attention has been devoted to direct laboratory comparisons of the relative effectiveness of reinforcement withdrawal and presentations of noxious stimuli in avoidance conditioning tasks. Stone (1961), using a free-operant, escape-avoidance schedule, compared the performance of 11 college Ss under both coin-loss (one cent) and shock-avoidance $(0.3$ to $1.0 \mathrm{~mA}$ for $30 \mathrm{msec})$ conditions. Both aversive events occurred at 20 -sec intervals unless a response was made. The Ss were tested for 30 min under each aversive stimulus, with order of stimuli counterbalanced. While large individual differences were obtained in the Ss' response patterns, Stone (1961) presented no evidence to suggest that either type of aversive stimulus event was responsible for these differences.

Although not concerned with these types of aversive

*This article is based on a thesis submitted to the Graduate School of the University of Southern Mississippi by the first author in partial fulfillment of the requirements for the Master of Arts degree. Reprint requests should be sent to the second author, Department of Psychology, University of Southern Mississippi, Hattiesburg, Mississippi 39401. events in an avoidance conditioning task, two additional studies are pertinent to the present experiment since they compared directly the effectiveness of withdrawal of positive reinforcing stimuli and presentation of noxious stimuli as punishment to reduce response patterns in monkeys. Tolman and Mueller (1964) reported that withdrawal of visual reinforcement and the presentation of loud noise contingent upon toe-sucking responses were both effective in suppressing the behavior. Similarly, McMillan (1967) concluded that electric shock and time-out from positive reinforcement both suppressed leverpressing to the same extent. Across several parameters in five experiments, McMillan (1967) stated that the similarities between the two types of punishers were more apparent than any differences between them.

These three studies seem to indicate a functional equivalence between withdrawal of positive reinforcement and presentation of noxious stimuli as aversive stimulus events in free-operant avoidance situations and as response-contingent punishers. One purpose of the present experiment was to investigate these two types of aversive events in a discrete-trial avoidance conditioning task with college Ss. Withdrawal of positive reinforcement consisted of brief omission of entertaining material (Bill Cosby recordings). Two intensities of tone ( $98 \mathrm{~dB}$ and $120 \mathrm{~dB})$ served as the noxious stimuli.

A second purpose of the present experiment was to investigate the effect of warning signal duration in human discrete-trial avoidance conditioning. Research concerning this parameter has not been extensive and has been confined to infrahuman Ss. Bolles (1967, p. 409) concluded that, in shuttlebox avoidance situations employing a delayed conditioning paradigm in which the warning signal remains on at least to the occurrence of the aversive stimulus, signal durations between 5 and $10 \mathrm{sec}$ resulted in optimal avoidance performance relative to longer or shorter durations. However, in a barpress avoidance task, Pearl and Edwards (1962) found better performance in rats using 
warning signal durations of 20 and $60 \mathrm{sec}$. While avoidance performance of Ss in these two groups did not differ significantly, both groups were superior to Ss given a 5-sec warning signal duration. Biederman (1969) assigned rats to one of three warning signal duration groups $(1.5,5$, or $15 \mathrm{sec})$ for 500 barpress, shock-avoidance trials. The next day, Ss were assigned to one of the three signal durations to generate a 3 by 3 factorial design and presented 500 additional trials. The results indicated that in each of the two sessions avoidance performance was positively associated with increased warning signal durations. Avoidance performance during the second session was not related to the Ss' signal duration condition in the first session. Based upon limited infrahuman evidence, it was predicted that better avoidance performance in human Ss in the present experiment would be obtained with a relatively long warning signal duration $(6 \mathrm{sec})$ as compared with a shorter duration $(2 \mathrm{sec})$ due, mainly, to an increased opportunity to make a correct response.

\section{METHOD}

\section{Subjects}

The Ss were 60 undergraduate students enrolled in psychology courses at the University of Southern Mississippi.

\section{Apparatus}

The apparatus consisted of a black wooden box, $9 \times 17 \frac{1}{2} \times$ 3 in. high. A microswitch was mounted in the midline of the top surface of the box, $4 \mathrm{in}$. from the edge nearest the $S$. A hinged 5 x $6 \frac{1}{2}$ in. panel was positioned over the microswitch. A $10-W$ green light bulb was mounted $1 \mathrm{in}$. from the back edge of the top surface of the box.

Four Hunter decade interval timers controlled warning signal duration, duration of the aversive stimuli, interstimulus interval (ISI) and intertrial interval (ITI). A Hunter Klockounter was used to record response latencies to the nearest $.01 \mathrm{sec}$. The aversive stimuli were two tone intensities $(98$ and $120 \mathrm{~dB}$ at $1,000 \mathrm{hps})$ and the omission of Bill Cosby comedy recordings. The tones were generated by a Precision E-310 sine-square wave signal generator and amplified by a Marietta CHB-30 audio amplifier. For recording omission, a Sony-Matic TC-105 tape recorder was modified so that during recording omission intervals the tape continued to play but without sound. The material taped for presentation was selections from Bill Cosby record albums (Warner Bros. W1518, W1567, W1606). The tones and recorded material were presented to Ss through Superex headphones.

\section{Design}

The 60 Ss were assigned randomly to one of six cells in a 3 by 2 factorial design consisting of three levels of aversive stimulus events and two levels of warning signal duration. Each group consisted of five male and five female Ss. A delayed conditioning procedure was used with light offset and initiation of the aversive stimulus occurring simultaneously. For one-half of the Ss, the maximum interval of the warning signal was $2 \mathrm{sec}$; for the remaining Ss the maximum duration was $6 \mathrm{sec}$. For all Ss the maximum duration of the three aversive stimuli was $5 \mathrm{sec}$. The aversive stimulus for one-third of the Ss in each of the two warning signal durations consisted of the $98-\mathrm{dB}$ tone, the $120-\mathrm{dB}$ tone, or recording omission. The ITI, as measured from the termination of the aversive stimulus interval to the onset of the warning signal for the subsequent trial, was $12 \mathrm{sec}$. During the ITI and warning signal interval a $60-\mathrm{dB}$ white noise was presented to Ss in both tone groups, while for Ss in the recording omission group the recordings played continuously during these intervals. An avoidance response during the warning signal interval immediately terminated the light and initiated the ITI. An escape response occurring within the 5-sec interval of the aversive stimulus immediately terminated the event and initiated the ITI. Responding during the ITI did not affect the response consequences on the following trial.

\section{Procedure}

Each S was tested individually in a normally illuminated room. For Ss receiving the tones the following instructions were given: "During this experiment you will experience some very loud sounds. From time to time the sound will come on. However, this need not happen and you will be able, if you want, to prevent these sounds from occurring. This is all I can tell you." The instructions for the recording omission group were as follows: "During this experiment you will be listening to some recorded material. From time to time the sound will go off. However, this need not happen and you will be able, if you want, to listen to the recordings without interruption. This is all I can tell you." At this point all Ss were asked if they wanted to continue in the experiment. Upon their consent, the E placed the headpnones on the $S$ and entered an adjoining experimental room to begin the trials. All Ss were given 40 trials according to the S's appropriate experimental condition. In addition to recording response latencies the $E$ observed each $S$ through a one-way mirror for any indication of overt discomfort as a result of the experimental procedures.

\section{RESULTS}

An acquisition criterion of 9 of 10 avoidance responses within the 40 trials was adopted. The 40 trials were divided into eight blocks of five trials each. The dependent measures included (a) the number of trials to reach the avoidance acquisition criterion, (b) the number of avoidance responses made across the eight trial blocks, and (c) the mean latency score across the trial blocks. The mean number of avoidance responses and the mean response latency scores across the trial blocks for the six experimental conditions are presented in Table 1.

A 3 by 2 analysis of variance (Winer, 1971) performed on the trials to criterion measure indicated no significant main effects or interaction for warning signal duration and aversive stimulus event $(p s>.10)$. The mean number of trials to reach the avoidance acquisition was $14.83(\mathrm{SD}=7.23)$.

A three-factor, repeated measures analysis of variance (Winer, 1971) performed on the number of avoidance responses made across trial blocks indicated a significant main effect for trial blocks, $F(7,378)=47.02, p<.001$. No other main effects or interactions were significant ( $>$ > .01). A Tukey (a) post hoc comparison test (Winer, 1971) performed on the trial blocks main effect indicated that (a) the number of avoidance responses increased significantly in each of the first three trial blocks $(p<.01)$, (b) significantly more avoidance responses were made in the last five trial blocks than in the first three trial blocks $(p<.01)$, and (c) the number of avoidance responses made across the last five trial 
Table 1

Mean Number of Avoidance Responses (AR) and Mean Response Latency (RL) Across Trial Blocks

\begin{tabular}{|c|c|c|c|c|c|c|c|c|c|c|}
\hline \multirow{2}{*}{$\begin{array}{c}\text { Aversive } \\
\text { Stimulus } \\
\text { Event }\end{array}$} & \multirow{2}{*}{$\begin{array}{c}\text { Warning } \\
\text { Signal } \\
\text { Duration }\end{array}$} & & \multicolumn{8}{|c|}{ Eight Blocks of Five Trials } \\
\hline & & & 1 & 2 & 3 & 4 & 5 & 6 & 7 & 8 \\
\hline \multirow[b]{2}{*}{$98 \mathrm{~dB}$} & $2 \mathrm{Sec}$ & $\begin{array}{l}\mathrm{AR} \\
\mathrm{RL}\end{array}$ & $\begin{array}{l}2.5 \\
2.88\end{array}$ & $\begin{array}{l}3.5 \\
2.02\end{array}$ & $\begin{array}{l}3.9 \\
1.77\end{array}$ & $\begin{array}{l}4.2 \\
1.74\end{array}$ & $\begin{array}{l}4.3 \\
1.79\end{array}$ & $\begin{array}{l}4.4 \\
1.77\end{array}$ & $\begin{array}{l}4.3 \\
1.79\end{array}$ & $\begin{array}{l}4.5 \\
1.67\end{array}$ \\
\hline & $6 \mathrm{Sec}$ & $\begin{array}{l}\text { AR } \\
\text { RL }\end{array}$ & $\begin{array}{l}2.3 \\
4.79\end{array}$ & $\begin{array}{l}3.5 \\
3.10\end{array}$ & $\begin{array}{l}4.2 \\
2.42\end{array}$ & $\begin{array}{l}4.5 \\
2.12\end{array}$ & $\begin{array}{l}4.5 \\
1.95\end{array}$ & $\begin{array}{l}5.0 \\
1.50\end{array}$ & $\begin{array}{l}4.8 \\
1.84\end{array}$ & $\begin{array}{l}5.0 \\
1.76\end{array}$ \\
\hline \multirow{2}{*}{$\begin{array}{l}\text { Bill } \\
\text { Cosby }\end{array}$} & $2 \mathrm{Sec}$ & $\begin{array}{l}\mathrm{AR} \\
\mathrm{RL}\end{array}$ & $\begin{array}{l}2.2 \\
3.39\end{array}$ & $\begin{array}{l}3.7 \\
2.12\end{array}$ & $\begin{array}{l}4.4 \\
1.27\end{array}$ & $\begin{array}{l}4.7 \\
1.09\end{array}$ & $\begin{array}{l}4.9 \\
1.09\end{array}$ & $\begin{array}{l}4.8 \\
1.05\end{array}$ & $\begin{array}{l}4.8 \\
1.18\end{array}$ & $\begin{array}{l}4.9 \\
1.07\end{array}$ \\
\hline & $6 \mathrm{Sec}$ & $\begin{array}{l}A R \\
R L\end{array}$ & $\begin{array}{l}3.1 \\
3.99\end{array}$ & $\begin{array}{l}4.3 \\
2.20\end{array}$ & $\begin{array}{l}4.4 \\
1.92\end{array}$ & $\begin{array}{l}4.5 \\
2.09\end{array}$ & $\begin{array}{l}4.5 \\
1.74\end{array}$ & $\begin{array}{l}4.4 \\
1.78\end{array}$ & $\begin{array}{l}4.3 \\
1.77\end{array}$ & $\begin{array}{l}4.5 \\
1.96\end{array}$ \\
\hline \multirow[b]{2}{*}{$120 \mathrm{~dB}$} & $2 \mathrm{Sec}$ & $\begin{array}{l}\mathrm{AR} \\
\mathrm{RL}\end{array}$ & $\begin{array}{l}1.7 \\
2.92\end{array}$ & $\begin{array}{l}4.3 \\
1.32\end{array}$ & $\begin{array}{l}4.7 \\
0.88\end{array}$ & $\begin{array}{l}4.9 \\
0.66\end{array}$ & $\begin{array}{l}5.0 \\
0.61\end{array}$ & $\begin{array}{l}4.9 \\
0.59\end{array}$ & $\begin{array}{l}5.0 \\
0.58\end{array}$ & $\begin{array}{l}5.0 \\
0.58\end{array}$ \\
\hline & $6 \mathrm{Sec}$ & $\begin{array}{l}\text { AR } \\
\text { RL }\end{array}$ & $\begin{array}{l}3.1 \\
5.38\end{array}$ & $\begin{array}{l}4.4 \\
2.04\end{array}$ & $\begin{array}{l}4.6 \\
1.30\end{array}$ & $\begin{array}{l}4.7 \\
1.13\end{array}$ & $\begin{array}{l}5.0 \\
0.78 \\
\end{array}$ & $\begin{array}{l}5.0 \\
0.65 \\
\end{array}$ & $\begin{array}{l}5.0 \\
0.59 \\
\end{array}$ & $\begin{array}{l}5.0 \\
0.59 \\
\end{array}$ \\
\hline
\end{tabular}

blocks did not differ significantly from each other $(\mathrm{p}>.05)$.

Inspection of the mean latency data as well as a consideration of the trials to criterion and trial blocks analyses indicated that the eight trial blocks could be appropriately subdivided into two components consisting of the mean response latencies across the first three and last five trial blocks for separate analyses. A three-factor, repeated measures analysis of variance performed on the first three trial blocks indicated a significant between-Ss main effect for warning signal duration, $F(1,54)=4.09, p<.05$. The main effect for aversive stimulus event and the between-Ss interaction was not significant $(p>.10)$. Significant within-Ss effects included (a) the trial block main effect, $F(2,108)$ $=79.84, \mathrm{p}<.001$, (b) the Trial Block by Aversive Stimulus interaction, $F(4,108)=2.66, p<.05$, and (c) the Trial Block by Warning Signal Duration interaction, $\mathrm{F}(2,108)=5.18, \mathrm{p}<.01$. A Tukey (a) post hoc comparison test for the Trial Block by Aversive Stimulus interaction yielded the following pertinent, significant comparisons: (a) response latencies for each of the three aversive stimuli decreased from Trial Block 1 to Trial Block $2(\mathrm{p}<.01)$, and (b) response latencies of $\mathrm{Ss}$ in the $98-\mathrm{dB}$ tone were longer than the latencies of $\mathrm{Ss}$ in the 120-dB group at both Trial Blocks 2 and $3(\mathrm{p}<.01)$. A Tukey (a) test performed on the Trial Block by Warning Signal Duration interaction indicated the following relevant pattern of significant comparisons: (a) response latencies for Ss in both the 2and 6-sec signal-duration groups decreased across each of the first three trial blocks $(p<.01)$, and $(b)$ at each of the first three trial blocks response latencies for Ss in the 6-sec signal duration group were longer than the latencies of Ss in the 2-sec duration group $(\mathrm{p}<.01)$.

A similar three-factor, repeated measures analysis performed on the response latencies over the last five trial blocks indicated a significant between-Ss main effect for aversive stimulus event, $F(2,54)=4.39$, $p<.05$. No other between- or within-Ss main effect or interactions were significant $(p>.05)$. The mean response latencies for the $98-\mathrm{dB}$ tone, recording omission, and 120-dB tone groups were $1.79,1.48$, and $0.68 \mathrm{sec}$, respectively. A Tukey (a) comparison test performed on the mean response latencies for the three groups indicated significant differences between each of the three aversive stimulus events $(p<.05)$.

\section{DISCUSSION}

The present experiment sought to determine the functional properties between two types of aversive stimulus events on human discrete-trial avoidance conditioning performance. The results indicated that "omission of entertaining material and the presentation of two intensities of loud tones did not differentially affect avoidance performance in terms of the number 'of avoidance responses made during the 40 trials. This general finding is not inconsistent with the results of a limited number of experiments directly comparing these two types of aversive events in free-operant avoidance and punishment situations (e.g., McMillan, 1967; Stone, 1961).

The only dependent measure to delineate differences in avoidance performance in the present study was response latency. With regard to the aversive stimulus events, the S's response latencies in each of the three groups decreased significantly over the first two trial blocks. Over Trial Blocks 2 and 3 , response latencies of $\mathrm{Ss}$ in the $98 \mathrm{-dB}$ group were significantly longer than the latencies of $\mathrm{Ss}$ in the $120-\mathrm{dB}$ group. These differences in response latencies were maintained over the last five trial blocks. Porter and Dawley (1966) found similar results for response latencies in a human escape conditioning task. Response latencies were significantly faster to a $115-\mathrm{dB}$ tone than to a 98-dB tone. The most striking finding with regard to the three aversive stimulus events concerned the avoidance latencies of Ss in the Bill Cosby group relative to the latencies of Ss in the 98- and 120-dB groups. That avoidance response latencies of $\mathrm{Ss}$ in the $120-\mathrm{dB}$ group were significantly shorter than latencies of Ss in the Bill Cosby group was not unexpected. However, the finding that Ss in the Bill Cosby group had significantly shorter avoidance response latencies than did Ss in the $98-\mathrm{dB}$ tone group was surprising and necessitates further research to support its validity. The fact the brief omission of entertaining material resulted in shorter response latencies than the onset of a more traditional aversive stimulus, as well as the nonsignificant differences between groups for the avoidance criterion and avoidance response measures, again raises the question of what constitutes an aversive stimulus event. As 
Leitenberg (1965) stated, the concept of "aversiveness" is a hypothetical construct and, therefore, is dependent upon specific experimental conditions and observable response measures for its definition. In the present discrete-trial avoidance conditioning situation, a functional equivalence between the withdrawal of a positively reinforcing stimulus and the presentation of a noxious stimulus was supported.

Previous research indicated that a longer warning signal duration would result in better avoidance due to an increased opportunity to make an avoidance response. In the present study, avoidance performance of Ss in terms of the trials to criterion and number of avoidance responses made was not differentially affected by warning signal duration. However, response latencies for both the 2- and 6-sec signal duration groups decreased significantly across the initial three trial blocks with latencies of Ss in the 6-sec group being significantly longer than latencies of Ss in the 2-sec group for each trial block. Infrahuman research has attempted to determine if warning duration contributes relatively more to the initial acquisition of an avoidance response or to its maintenance (e.g., Bolles, 1967). Although the present experiment was not designed to directly answer this question, the results do suggest that any benefit accruing from long warning signal durations in human barpress avoidance situations would be minimal. Whatever differential effect warning signal durations may have on avoidance conditioning would be expected as a result of long-latency avoidance and/or escape responses occurring during the initial trials.

\section{REFERENCES}

Ader, R., \& Tatum, R. Free-operant avoidance conditioning in human subjects. Journal of the Experimental Analysis of Behavior, 1961, 4, 275-286.

Baer, D. M. Escape and avoidance responses of the pre-school children to two schedules of reinforcement withdrawal. Journal of the Experimental Analysis of Behavior, 1960, 3, 155-159.

Banks, R. K. Effect of pairing a stimulus with presentations of the UCS on the extinction of an avoidance response in humans. Journal of Experimental Psychology, 1965, 70, 294-299.
Baron, A., \& Kaufman, A. Human free-operant avoidance of "time-out" from monetary reinforcement. Journal of the Experimental Analysis of Behavior, 1966, 9, 557-565.

Biederman, $G$. The role of the $C S$ and avoidance period duration in discriminated avoidance conditioning. Quarterly Journal of Experimental Psychology, 1969, 21, 322-329.

Bolles, R. C. Theory of motivation. New York: Harper \& Row, 1967.

Leitenberg, $H$. Is time-out from positive reinforccment an aversive event? Psychological Bulletin, 1965, 64, 428-441.

McMillan, D. E. A comparison of the punishing effects of response-produced shock and response-produced time out. Journal of the Experimental Analy sis of Behavior, 1967, 10, 439-449.

Miller, F. D., Kalin, R., Eckenroth, W., Meyer, P. Acquisition variables in human avoidance behavior. Psychonomic Science, 1970, 21, 233-235.

Moffat, G. H. Avoidance conditioning in young children with interruption of positive stimulus as the aversive event. Journal of Experimental Child Psychology, 1972, 13, 21-28.

Moffat, G. H., \& Miller, F. D. Escape and avoidance conditioning with omission of entertaining material as the aversive event. Psychonomic Science, 1970, 18, 97-98.

Pearl, J., \& Edwards, R. E. Delayed avoidance conditioning: Warning stimulus (CS) duration. Psychological Reports, 1962, $11,375-380$

Penney, R. K., \& Croskery, J. Instrumental avoidance conditioning of anxious and nonanxious children. Journal of Comparative \& Physiological Psychology, 1962, 55, 847-849.

Porter, J. \& Dawley, J. Instrumental escape as a function of UCS intensity, UCS retention, and type of instructions. Psychonomic Science, 1966, 5, 171-172.

Presbie, R. Effects of instructions on human free-operant avoidance conditioning with white noise. Psychological Reports, 1970, 27, 895-898.

Stone, G. Nondiscriminated avoidance behavior in human subjects. Science, 1961, 133, 641-642.

Tolman, C., \& Mueller, M. Laboratory control of toe-sucking in young Rhesus monkey by two kinds of punishment. Journal of the Experimental Analy sis of Behavior, 1964, 7, 323-325.

Weiner, $H$. Response cost and aversive control of human operant behavior. Journal of the Experimental Analysis of Behavior, $1963,6,415-421$.

Winer, B. J. Statistical principles in experimental designs.. (2nd ed.) New York: McGraw-Hill, 1971.

(Received for publication January 12, 1974.) 